\title{
FABRICAÇÃO DE CÉLULAS SOLARES SENSIBILIZADAS POR CORANTES ORGÂNICOS: MALUS DOMESTICA
}

Leonardo Ricardo Bernardes da Conceição'; Ana Lucia Ferreira de Barros2; Rajendran Suresh Babu²; Breno Christianes Ferreira²; Felipe Macedo Moura dos Santos $^{2}$; Francisco Capuzo Ferreira ${ }^{2}$

1 CEFET/RJ - Rua General Canabarro, 485, Maracanã; Rio de Janeiro/RJ; leonardo.rbconceicao@gmail.com

${ }^{2}$ CEFET/RJ - Rua General Canabarro, 485, Maracanã; Rio de Janeiro/RJ

Resumo: Nestas últimas décadas houve um crescente interesse a respeito das formas alternativas de energia, com o propósito de reduzir o uso de fontes não renováveis ou prejudiciais ao meio ambiente, como o petróleo e seus decorrentes. As células solares compostas por corantes orgânicos vieram com uma nova possibilidade para apresentar uma solução sustentável na geração de energia elétrica. Neste trabalho, realizado no Laboratório de Física Experimental Aplicada (LaFEA), foram realizadas medidas de caracterização estrutural, eletroquímica e um estudos das propriedades químicas das moléculas das células. Os resultados obtidos são apresentados, assim como a sua comparação junto a literatura.

Palavras-Chave: Células solares; Corantes orgânicos; Geração de energia elétrica.

\section{MANUFACTURING SOLAR CELLS SENSITIZED BY ORGANIC DYES: MALUS DOMESTICA}

\begin{abstract}
In recent decades there has been a growing interest regarding alternative forms of energy, with the purpose of reducing the use of non-renewable or environmentally harmful sources, such as oil and its derivatives. Solar cells composed of organic dyes have come up with a new possibility to present a sustainable solution for electric power generation. In this work, carried out at the Laboratory of Applied Experimental Physics (LaFEA), measurements were made of structural, electrochemical characterization and chemical properties of cells. The obtained results are presented, as well as their comparison with the literature.
\end{abstract}

Keywords: Renewable energy. Solar cells; Organic dyes; Electricity generation. 


\section{INTRODUÇÃO}

A utilização da energia solar se mostra como uma fonte abundante de fornecimento de energia elétrica. Em países tropicais como o Brasil, seus recursos podem ser melhores utilizados, pois possuem uma grande incidência de radiação solar e fazendo-se presente em grande quantidade em todas épocas do ano. Nos dias atuais é bastante utilizado na indústria células solares de silício por sua larga escala de produção. No entanto, o custo de produção das células solares com base no material de cristais de silício em comparação com as células solares sensibilizadas por corantes (DSSCs) é alto. As DSSCs despertaram grande atenção e são de grande interesse devido às vantagens de seu menor custo de fabricação [1].

As DSSCs são dispositivos que convertem energia solar em energia elétrica através da sensibilização à luz. Da mesma forma que estabelecida em semicondutores de banda larga de energia [2]. As DSSC's, também conhecidas como células de Grätzel, vem atraindo um grande interesse devido ao seu custo mínimo de produção e sua forma sustentável na utilização de corantes orgânicos [3].

\section{METODOLOGIA}

Seu sistema de funcionamento é formado por um contra eletrodo, um eletrólito contendo iodeto e íons tri-iodeto, além de um corante nano-cristalino poroso semicondutor absorvido por eletrodo. O corante que atua como sensibilizador nas DSSC's desempenha uma tarefa importante na absorção e conversão do raio de luz incidente em eletricidade.

A célula foi preparada utilizando o dióxido de titânio $\left(\mathrm{TiO}_{2}\right)$ como uma camada semicondutora e nela foi aplicado o corante natural extraído da maçã (Malus domestica). Filmes finos de $\mathrm{TiO}_{2}$ foram depositados em um filme revestido com óxido de flúor dopado com estanho (FTO) transparente através do método do spin coating. A caracterização estrutural da célula, foi realizada no Microscópio de Força Atômica (AFM), utilizando o software Nanosurf EasyScan 2, para verificar a estrutura morfológica do $\mathrm{TiO}_{2}$ depositado no filme fino. O Microscópio de Varredura Eletrônica (MEV), modelo JEOL®JSM-7100F, foi usado para análise de características microestruturais.

No estudo das propriedades químicas das moléculas do corante foi utilizada a técnica de Espectroscopia de Infravermelho com Transformada de Fourier (FTIR), utilizando o Espectrômetro Agilent Cary 630. Verificou-se a importância nesta análise, o fato do extrato do corante de maçã possuir radicais de antocianina, importantes na geração do processo de emissão de luz. Por fim, para análise eletroquímica foi utilizado o Multi-potenciostato (IVIUM Compactstat) em conjunto com um Solarímetro Digital Portátil $(E K O \circledast M S-01)$, emitindo irradiância na célula para realização do ensaio.

\subsection{Preparação do Corante Orgânico}


O corante orgânico natural foi preparado a partir da casca da maçã (Malus domestica), pois ela contém uma cor característica que é própria para o conteúdo da antocianina [4]. A fruta foi limpa com água destilada e sua casca retirada. Foi adicionado $25 \mathrm{~g}$ de casca de maçã na quantidade de $50 \mathrm{ml}$ de solvente. Para a escolha do solvente, foram realizados testes de solubilidade com: água destilada, álcool isopropílico, etanol e acetona. O etanol foi escolhido como melhor solvente para a utilização do experimento, que apresentou melhor pigmentação em relação às outras. A solução foi então filtrada e guardada em recipiente fechado e refrigerado.

\subsection{Preparação do Anodo}

Após a separação da quantidade exata dos componentes: polietilenoglicol $(0,15 \mathrm{~g})$, dióxido de titânio $(0,5 \mathrm{~g})$, água destilada $(3 \mathrm{ml})$ e ácido acético $(3 \mathrm{ml})$, a solução foi colocada no ultrassom para realização da mistura. O fotoanodo é preparado a partir da deposição de uma camada de $\mathrm{TiO}_{2}$ nanocristalino sob um substrato de vidro condutor transparente, o qual contém óxido de estanho dopado com flúor. Para a realização da deposição da solução de $\mathrm{TiO}_{2}$ no substrato de filme $\mathrm{FTO}$, foi usada a técnica de spin coating a $1000 \mathrm{rpm}$ por 10 segundos. Os filmes prontos estão mostrados na Figura (1). Posteriormente foi feito o recozimento da amostra no forno mufla a $450^{\circ} \mathrm{C}$ por 30 minutos para cristalizar a estrutura do semicondutor [5].

Figura 1. Filmes finos de FTO com deposição da solução de $\mathrm{TiO}_{2}$.

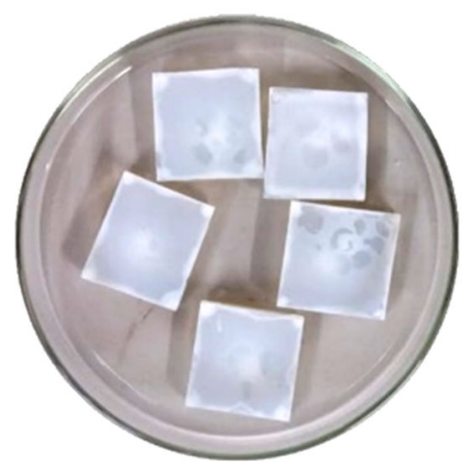

\subsection{Preparação do Catodo}

O contra eletrodo, ou catodo, é o componente das DSSC's que faz a regeneração dos íons presentes no eletrólito. Uma fina camada de material condutor é depositada sobre um vidro de FTO, formando o catodo [6]. A solução condutora de platina foi preparada misturando 0,5 gramas de pó de platina e $5 \mathrm{ml}$ de etanol, em seguida, houve a mistura da solução no ultrassom durante 30 minutos. Após a realização da mistura, foi espalhado uniformemente no substrato de vidro FTO 
utilizando a micropipeta e levado ao forno mufla a $350{ }^{\circ} \mathrm{C}$ por 30 minutos, logo após o recozimento o contra eletrodo foi mantido em temperatura ambiente.

\subsection{Preparação do Eletrólito}

O eletrólito foi preparado para ser injetado entre os dois eletrodos das células e auxiliar no transporte dos elétrons [7]. O preparo do eletrólito constitui-se na mistura no ultrassom, dos componentes: polietilenoglicol $(0,2 \mathrm{~g})$, acetonitrila $(5 \mathrm{ml})$, lodo $(0,19 \mathrm{~g})$ e iodeto de potássio $(2,075 \mathrm{~g})$ medidos respectivamente em suas devidas quantidades.

\section{RESULTADOS E DISCUSSÃO}

\subsection{Microscopia de Força Atômica (AFM)}

O microscópio de força atômica foi utilizado para gerar imagens 3D com resolução microscópica, proporcionando o estudo da morfologia de superfícies. Para uma boa absorção do corante e bom fluxo de elétrons no semicondutor, é esperada uma deposição uniforme e mesoporosa. Podemos observar na Figura 2 a imagem topográfica de um filme de $\mathrm{TiO}_{2}$ em escala micrométrica de $25 \mu \mathrm{m}$, o qual apresenta um bom resultado quando comparado com a literatura [8].

Figura 2. Imagem tridimensional do AFM - Filme de $\mathrm{TiO}_{2}$.

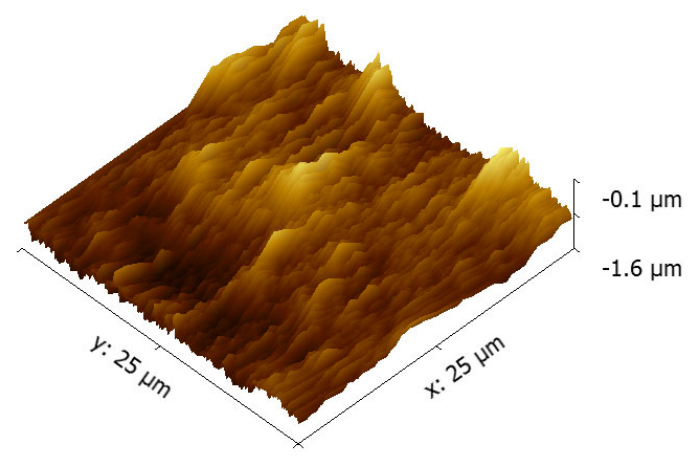

\subsection{Microscópio Eletrônico de Varredura (MEV)}

Com o propósito de conhecer melhor sobre a composição e topografia do filme de $\mathrm{TiO}_{2}$ foi usado a Microscópio Eletrônico de Varredura (MEV). Na Figura 3, apresenta o filme de $\mathrm{TiO}_{2}$ utilizando uma aproximação de 50.000 vezes no aparelho. Comparado com a literatura [9], constata-se que o filme possui uma quantidade uniformemente espalhada de nano poros facilitando a absorção do corante. Porém, 
se presentes em grande quantidade fazem com que o fluxo de elétrons no filme semicondutor fique comprometido.

Figura 3. Imagem Microscópica - Filme de $\mathrm{TiO}_{2}$.

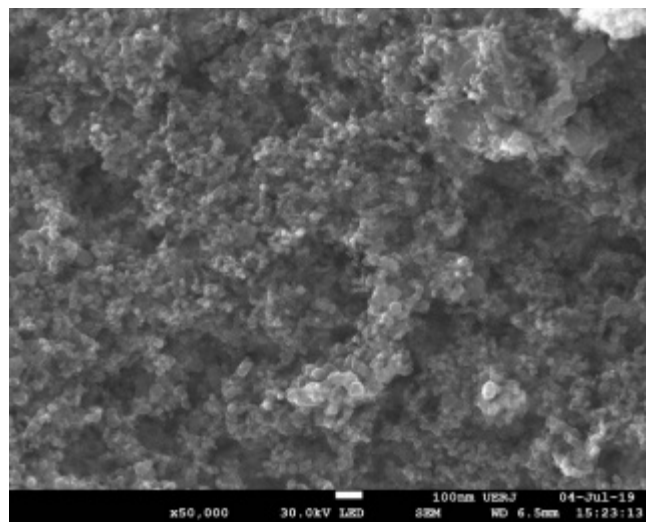

\subsection{Espectroscopia por Infravermelho com Transformada de Fourier (FTIR)}

O FTIR consiste em um método de caracterização ótica que identifica os elementos químicos da amostra. Nesse contexto foi utilizado o FTIR para identificar as ligações principais que estão presentes na amostra de maçã, incluindo a antocianina. Como podemos observar na Figura 4, no intervalo de números de onda entre $3800 \mathrm{~cm}^{-1}$ e $3100 \mathrm{~cm}^{-1}$ é encontrado uma banda referente à ligação $\mathrm{H}-\mathrm{O}-\mathrm{H}$, que indica a presença de água e do etanol que também é utilizado como solvente. $\mathrm{O}$ intervalo de $3000 \mathrm{~cm}^{-1}$ e $2800 \mathrm{~cm}^{-1}$ aparece uma ligação C-O-C, do radical da antocianina, e no intervalo entre $1600 \mathrm{~cm}^{-1}$ e $1500 \mathrm{~cm}^{-1}$ refere-se à ligação $\mathrm{C}=\mathrm{C}$, existente também na estrutura aromática das antocianinas [10].

Figura 4. Espectro de FTIR - Extrato da maçã.

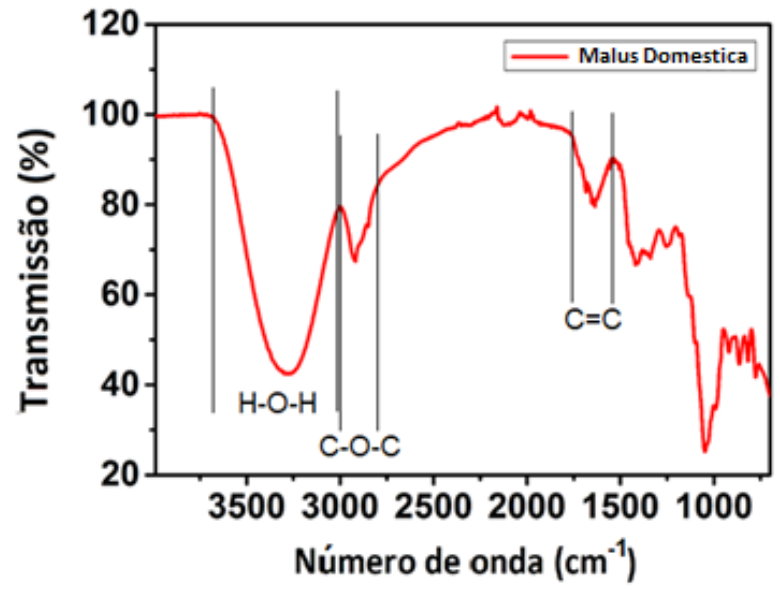

\subsection{Medidas da Performance Fotovoltaíca}


A conclusão da montagem da célula é realizada com o levantamento das curvas características $\mathrm{V}$ x I (tensão versus corrente) na determinação da eficiência das células solares. Esse processo consiste na utilização de um potenciostato em conjunto com um solarímetro portátil, sobre a célula de extrato de casca de maçã. Com a curva característica de V x I, pode-se coletar algumas informações importantes em relação ao funcionamento das células solares, como por exemplo a tensão de circuito aberto (Voc), a corrente de curto-circuito (ISC), o fator de preenchimento (FF) e a eficiência de conversão de fótons em elétrons $\eta$.

O fator de preenchimento $(F F)$ basicamente determina a eficiência de conversão de energia em célula solar, através da razão entre o produto entre a voltagem máxima e corrente máxima e o produto entre a voltagem de circuito aberto e a corrente de curto circuito, como apresentado na seguinte equação:

$$
F F=\frac{V_{\max } \cdot I_{\max }}{V_{o c} I_{s c}}
$$

O rendimento de uma célula solar representa a taxa de conversão de energia solar em energia elétrica que um dispositivo pode entregar, e é calculado através da razão entre a potência máxima sobre a potência de luz incidente versus a área da célula $(A)$, como apresentado na seguinte relação:

$$
\eta=\frac{P_{\max }}{P_{\text {inc }} \cdot A}=\frac{F F \cdot V_{o c} \cdot I_{s c}}{P_{i n c} \cdot A}
$$

Nos nossos resultados, obtivemos como voltagem de circuito aberto o valor de $0,52 \mathrm{~V}$, para a corrente de curto circuito o valor foi de 0,622 $\mathrm{mA}$, o fator de preenchimento resultou no valor de 0,491 e a eficiência final de conversão de energia alcançou o resultado de $0,95 \%$. A Figura 5 mostra o comportamento obtido da curva ( $V \times$ I) para a célula fabricada [11], e a Tabela 1 mostra a comparação de nossos resultados com alguns outros corantes orgânicos.

Figura 5. Curva V x I da Célula Solar Sensibilizada pela Maçã.

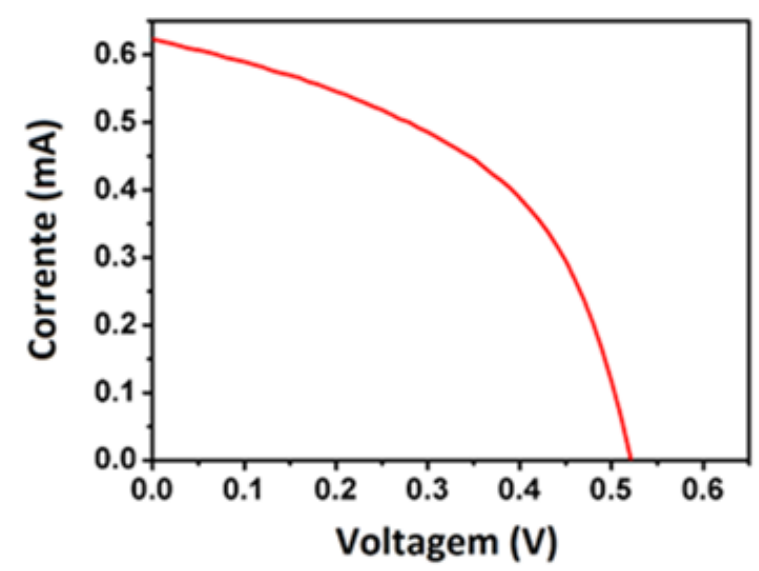

Tabela 1. Medidas da Performance Fotovoltaica das células orgânicas naturais. 
V SIINTEC INTERNATIONAL SYMPOSIUM ON INNOVATION AND TECHNOLOGY

\begin{tabular}{l|l} 
CIRCULAR ECONOMY & ECONOMIA CIRCULAR
\end{tabular}

\begin{tabular}{|c|c|c|c|c|c|}
\hline Corante & $\begin{array}{c}\mathrm{I}_{\mathrm{sc}} \\
\left(\mathrm{mA} / \mathrm{cm}^{2}\right)\end{array}$ & $\begin{array}{c}\mathrm{V}_{\mathrm{oc}} \\
(\mathrm{V})\end{array}$ & $F F$ & $\begin{array}{c}\eta \\
(\%)\end{array}$ & Ref. \\
\hline Malus Domestica & 0,622 & 0,52 & 0,491 & 0,95 & Este artigo \\
\hline Thunbergia erecta & 0,27 & 0,55 & 0,4 & 0,37 & {$[3]$} \\
\hline Lithospermum & 0,140 & 0,33 & 0,58 & 0,03 & {$[4]$} \\
\hline
\end{tabular}

\section{CONCLUSÃO}

Diante do exposto, vimos que a maçã (Malus domestica) é uma excelente escolha como sensibilizador natural para as células orgânicas, apresentando 0,95\% de eficiência. Foram feitas análises da morfologia, ótica e eletroquímica do fotoeletrodo revestido de $\mathrm{TiO}_{2}$. O contra eletrodo com revestimento de platina apresentou resultado satisfatório na composição da célula e a solução de eletrólito feita em laboratório cumpriu sua função fazendo com que o corante seja regenerado pelos íons. Os resultados da pesquisa apresentada neste trabalho, ainda se encontra em fase inicial, e procuramos através da utilização de diferentes compostos orgânicos aumentar ainda mais sua eficiência e tornar essa forma de geração de energia mais competitiva diante das células fotovoltaicas convencionais.

\section{Agradecimentos}

Agradeço à minha orientadora de mestrado a Profa. Dra. A. L. F. de Barros. As medidas realizadas no MEV, ao Prof. Dr. Hector Costa (CEFET) e ao Dr. Victor Santos Ramos da Universidade do Estado do Rio de Janeiro (UERJ). Ao pós-doutorando PNPD - CAPES Dr. R. Suresh Babu e aos alunos de graduação e pós-graduação do LaFEA.

\section{REFERÊNCIAS}

1 GONG, Jinlong; LI, Can; WASIELEWSKI, Michael R. Advances in solar energy conversion. Chemical Society Reviews, v. 48, n. 7, p. 1862-1864, 2019.

${ }^{2}$ BAKAR, Suriani Abu et al. Improved DSSC photovoltaic performance using reduced graphene oxide-carbon nanotube/platinum assisted with customised triple-tail surfactant as counter electrode and zinc oxide nanowire/titanium dioxide nanoparticle bilayer nanocomposite as photoanode. Graphene Technology, v. 4, n. 1-2, p. 17-31, 2019. 
${ }^{3}$ FERREIRA, B. C. et al. Influence of nanostructured TiO2 film thickness in dyesensitized solar cells using naturally extracted dye from Thunbergia erecta flowers as a photosensitizer. Optical Materials, v. 86, p. 239-246, 2018.

4 SAMPAIO, D. M. et al. Investigation of nanostructured TiO 2 thin film coatings for DSSCs application using natural dye extracted from jabuticaba fruit as photosensitizers. Ionics, v. 25, n. 6, p. 2893-2902, 2019.

${ }^{5}$ WATANABE, Marcos Norio et al. Fabrication and Electrical Characterization of MOS Solar Cells for Energy Harvesting. In: 33rd Symposium on Microelectronics Technology and Devices (SBMicro). IEEE, 2018. p. 1- 2018.

${ }^{6}$ GONG, Jiawei et al. Review on dye-sensitized solar cells (DSSCs): Advanced techniques and research trends. Renewable and Sustainable Energy Reviews, v. 68, p. 234-246, 2017.

7 SU'AIT, Mohd Sukor; RAHMAN, Mohd Yusri Abd; AHMAD, Azizan. Review on polymer electrolyte in dye-sensitized solar cells (DSSCs). Solar Energy, v. 115, p. 452-470, 2015.

8 HAMANN, Thomas W. The end of iodide? Cobalt complex redox shuttles in DSSCs. Dalton Transactions, v. 41, n. 11, p. 3111-3115, 2012.

9 LI, Lin et al. Double-layered $\mathrm{NiO}$ photocathodes for p-type DSSCs with record IPCE. Advanced Materials, v. 22, n. 15, p. 1759-1762, 2010.

10 KARUNAKARAN, Santhosh Kumar et al. Recent progress in inkjet-printed solar cells. Journal of Materials Chemistry A, v. 7, n. 23, p. 13873-13902, 2019.

11 SAMPAIO, D. M.; THIRUMAL, E.; DE BARROS, A. L. F. The effect of photo-anode surface morphology and gel-polymer electrolyte on dye-sensitized solar cells with natural dyes. Journal of Materials Science: Materials in Electronics, v. 27, n. 9, p. 9953-9961, 2016. 